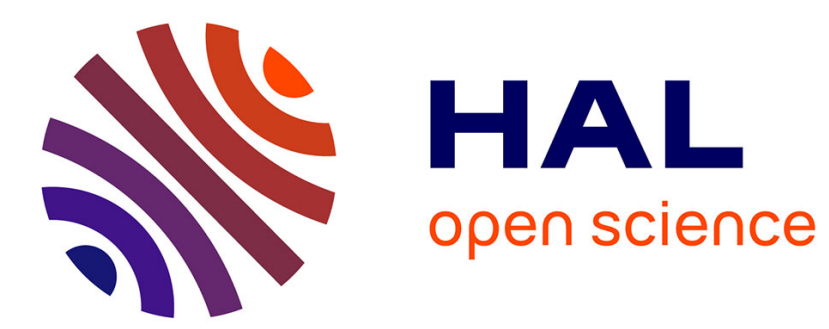

\title{
DEPOSITION OF CUBIC BORON MONOPHOSPHIDE FROM BBr3 AND PBr3: A REACTION MECHANISM
}

\author{
E. Kelder, P.J. van Der Put, J. Becht, J. Schoonman
}

\section{- To cite this version:}

E. Kelder, P.J. van Der Put, J. Becht, J. Schoonman. DEPOSITION OF CUBIC BORON MONOPHOSPHIDE FROM BBr3 AND PBr3: A REACTION MECHANISM. Journal de Physique IV Proceedings, 1991, 02 (C2), pp.C2-201-C2-208. 10.1051/jp4:1991225 • jpa-00249812

\section{HAL Id: jpa-00249812 https://hal.science/jpa-00249812}

Submitted on 1 Jan 1991

HAL is a multi-disciplinary open access archive for the deposit and dissemination of scientific research documents, whether they are published or not. The documents may come from teaching and research institutions in France or abroad, or from public or private research centers.
L'archive ouverte pluridisciplinaire HAL, est destinée au dépôt et à la diffusion de documents scientifiques de niveau recherche, publiés ou non, émanant des établissements d'enseignement et de recherche français ou étrangers, des laboratoires publics ou privés. 
Colloque C2, suppl. au Journal de Physique II, Vol. 1, septembre 1991

\title{
DEPOSITION OF CUBIC BORON MONOPHOSPHIDE FROM $\mathrm{BBr}_{3}$ AND $\mathrm{PBr}_{3}$ : A REACTION MECHANISM
}

\author{
E.M. KELDER, P.J. VAN DER PUT, J.G.M. BECHT and J. SCHOONMAN \\ Laboratory for Inorganic Chemistry, Delft University of \\ Technology, Julianalaan 136, NL-2628 BL Delft, The Netherlands
}

\begin{abstract}
The CVD growth kinetics of polycrystalline cubic BP at atmospheric pressure were studied for the BBr3-PBr3-H2 system using in situ thermogravimetry. In the temperature range $1050-1350 \mathrm{~K}$ the deposition obeys Langmuir-Hinshelwood kinetics having two different activation enthalpies. These are consistent with different rate limiting reactions in two temperature regimes. At low temperature PBr3 is the main adsorbed species and the activation enthalpy is $224 \mathrm{~kJ} / \mathrm{mole}$ due to substrate-phosphorus bond breaking of chemisorbed phosphorus species. At higher temperatures when the main adsorbed species is $\mathrm{P} 2$ the reaction is determined by an activation enthalpy of $247 \mathrm{~kJ} / \mathrm{mole}$ due to $\mathrm{P}=\mathrm{P}$ bond breaking of the $\mathrm{P}_{2}$ species at the surface. The order in $\mathrm{H2}$ decreases with temperature from $1 / 2$ at low temperature to zero at high temperature. The effect of the gas phase hydrogen partial pressure on the growth kinetics is explained by a higher affinity of $\mathrm{Hz}$ towards the substrate-phosphorus bond than towards the $\mathrm{P}=\mathrm{P}$ bond of adsorbed $\mathrm{Pz}$.
\end{abstract}

1. - Introduction.

The synthesis and characterization of two crystalline boron phosphides have been reported, i.e. cubic boron monophosphide $\mathrm{BP} / 1 /$, and a rhombohedral boron subphosphide $\mathrm{B} 6 \mathrm{P}$ or $\mathrm{B}_{13} \mathrm{P} 2 / 2 /$. Amorphous boron phosphides have been described as boron rich boron phosphide a-BxP, with $x$ ranging from 3 to $13 / 3,4 /$.

$\mathrm{BP}$ is a III-V semiconductor having an indirect bandgap of $2 \mathrm{eV} / 5 \%$. BP is very hard and resistant to chemical corrosion $/ 6 /$. It dissolves under hydrothermal conditions in concentrated nitric acid and alkali hydroxide. It oxidizes in air above $800{ }^{\circ} \mathrm{C}$ with formation of $\mathrm{BPO}_{4} / 1 \%$. Therefore, cubic $\mathrm{BP}$ is an interesting compound for thin film applications.

$B P$ dissociates into a lower phosphide $B 6 P$ and gaseous phosphorus if heated above $700{ }^{\circ} \mathrm{C}$. This dissociation precludes synthesis of $\mathrm{BP}$ directly from the elements since the melting point of boron is over $2000{ }^{\circ} \mathrm{C}$. In order to develop thin films of BP Chemical Vapor Deposition (CVD) is used in a reducing hydrogen atmosphere with bromide reactants. The reaction mechanism has been shown previously to obey Langmuir-Hinshelwood kinetics $/ 4,7 /$. At about $925^{\circ} \mathrm{C}$ a transition has been observed in the growth kinetics, which has previously been shown to result from a change in adsorbed phosphorus containing species, i.e. from $\mathrm{PBr} 3$ to $\mathrm{P} 2$. This change was also confirmed by thermodynamic calculations. However, the calculated energies observed from a least squares $f i t$, remain to be explained in terms of the observed Langmuir-Hinshelwood reaction mechanism. This assessed reaction mechanism is discussed briefly. Here we shall report on the assignments of the energies involving chemical bonds between species. Finally we shall discuss the role of the carrier gas hydrogen on the reaction growth rate, below and above the transition temperature. 
2. -Experimental aspects.

A thermobalance CVD set-up equipped with a vertical hot-wall fused-silica tube reactor (ID $26 \mathrm{~mm}$ ) as described previously $/ 4,7 /$ is used to determine growth rates of polycrystalline cubic $\mathrm{BP}$ as a function of temperature, $\mathrm{BBr}, \mathrm{PBr}$, and $\mathrm{H} 2$ reactant gas partial pressures at atmospheric pressure. Mixtures of helium and hyorogen are used as carrier gases. Substrates were alumina chips cleaned as described previously $/ 4,7 /$.

3. - Results and discussion.

An experimental CVD diagram of the solid phases as reported earlier /7/ is shown in Figure 1. Here we shall limit the discussion to the regime of cubic BP formation.

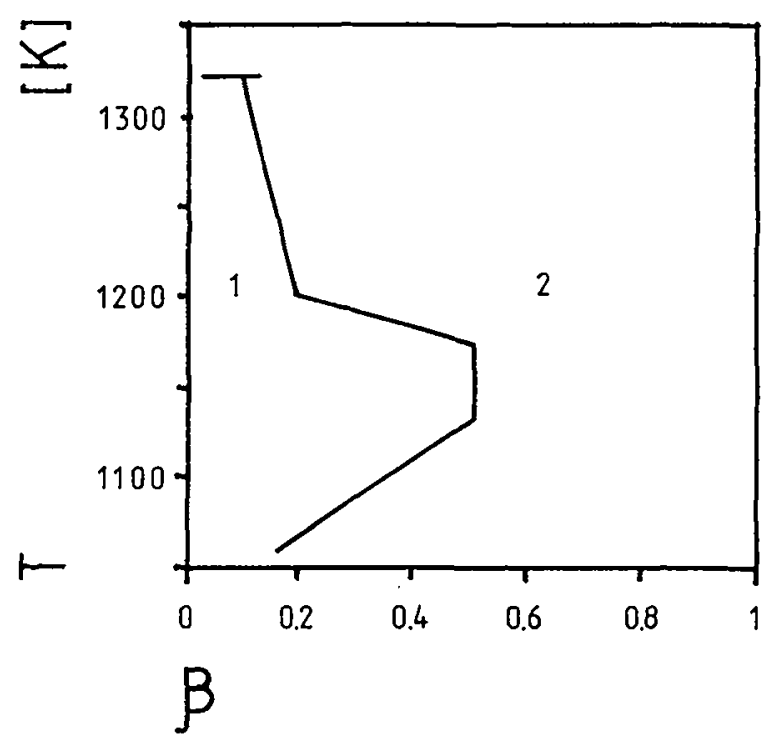

Fig. 1. Process conditions for deposition of polycrystalline cubic boron monophosphide BP (1), and amorphous boron phosphide BxP (2), with $x$ ranging from 3 to 13 and $\beta=p(B B r 3) /(p(B B r 3)+p(P B r 3))$.

Growth rate measurements were performed by changing input partial pressures and temperature. We observed for the growth rate at low BBr 3 input pressure a linear increase with BBr3 vapor pressure. Deviation from linearity occurs at higher reactant partial pressures (Fig. 2). For $\mathrm{PBr} 3$ we find at zero input partial pressure boron formation, at low input amorphous $B \times P$ formation, and above certain input partial pressures a steep increase in the BP growth rate, which decreases exponentlally at still higher input. The order in the $\mathrm{PBr} 3$ for high input changes above $925^{\circ} \mathrm{C}$ from -1 to $-1 / 2$ (Fig. 3). 


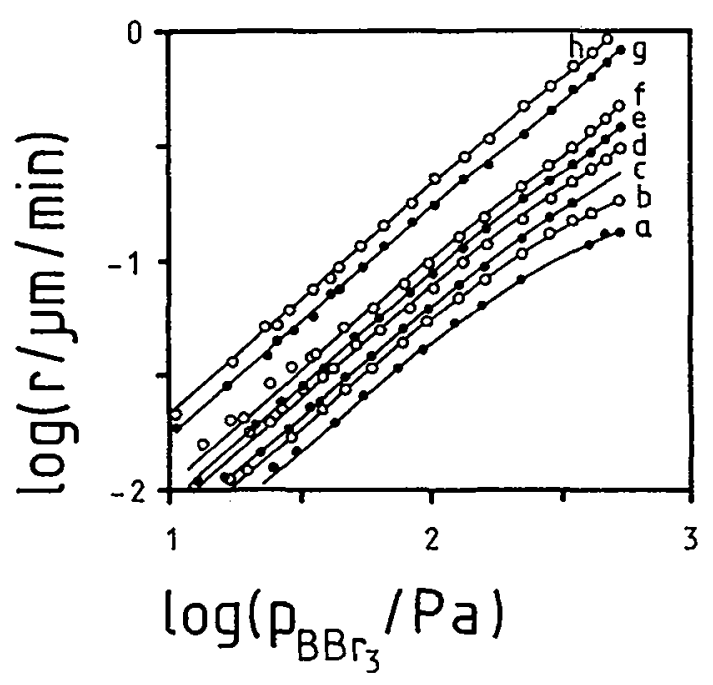

Fig. 2. Logarithmic plot of the growth rate $r$ versus $B B r 3$ pressure for several temperatures $\left({ }^{\circ} \mathrm{C}\right)$ at constant $\mathrm{PBr} 3$ pressure $(405 \mathrm{~Pa})$. a: $800 ;$ b: 821 ; c: 840 d: 860 ; e: $880 ;$ f: $902 ; \mathrm{g}$ : 931 ; h: 962 .

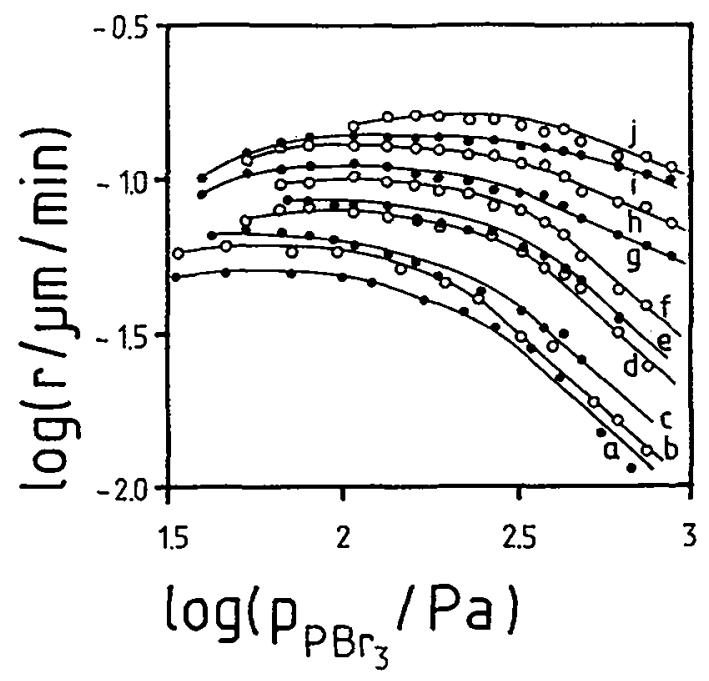

Fig. 3. Logarithmic plot of the growth rate $r$ versus $\mathrm{PBr} 3$ pressure for several temperatures $\left({ }^{\circ} \mathrm{C}\right)$ at constant $\mathrm{BBr} 3$ pressure (45 Pa). a: 800; b: 821 c: 840 d: $860 ;$ e: 881 ; f: $904 ; \mathrm{g}: 906 ; \mathrm{h}: 967$ 1: $1008 ; j: 1058$.

This change in reaction order can be understood by assuming Langmuir-Hinshelwood adsorption behavior /8,9/for different gas species which compete for the same adsorption sites. The temperature dependence of the growth rate is different at temperatures below and above $925^{\circ} \mathrm{C}$. According to thermodynamic equilibrium calculations, at low temperatures, the competitive species are $\mathrm{BBr} / 10 /$ and $\mathrm{PBr}$, whereas at high temperature the competitive species are $\mathrm{BBr} / 10 /$ and $\mathrm{P} 2 . \mathrm{P} 2$ is assumed to adsorb dissociatively, requiring 2 adjacent sites simultaneously, and leading to a reaction order of -1/2 for high input $18,9 /$. Actually $\mathrm{PBr} 3$ is detected at low temperatures at the outlet of the reactor, whereas at higher temperatures it is not detected. At low temperatures where $\mathrm{P}_{4}$ is thermodynamically in excess $/ 7 /$ compared to $\mathrm{P}_{2}$ the reactive species is $\mathrm{PBr}$, whereas at high temperature where $\mathrm{P}_{2}$ is thermodynamically in excess compared to $\mathrm{P}_{4}$, and no $\mathrm{PBr} 3$ is available, the reactive species is $\mathrm{P}_{2}$. $\mathrm{P}_{4}$ is not involved in the reaction according to our model. The growth rates for both mechanisms are:

$r 1=\frac{k_{r} 1 K_{B} P_{B} K_{P} P_{P}}{\left(1+K_{B} P_{B}+K_{P} P P\right)^{2}}$

$$
r z=\frac{K_{r} 2 K_{B P B}\left(K_{2} P_{P 2}\right)^{1 / 2}}{\left(1+K_{B P B}+\left(K_{2} P_{P 2}\right)^{1 / 2}\right)^{2}}
$$

$\mathrm{r} 1, \mathrm{r2}$ : growth rate at $\mathrm{T}<925{ }^{\circ} \mathrm{C}$, and $\mathrm{T}>925^{\circ} \mathrm{C}$, respectively.

$\mathrm{kr} 1, \mathrm{kr} 2$ : reaction rate constant for reaction $\mathrm{r} 1$ and $\mathrm{r} 2$, respectively.

$\mathrm{KB}, \mathrm{KP}, \mathrm{KP2}$ : heat of adsorption for species $\mathrm{BBr}, \mathrm{PBr} 3$, and $\mathrm{P2}$, respectively.

$\mathrm{PB}, \mathrm{PP}, \mathrm{PP2}$ : partial pressure of species $\mathrm{BBr}, \mathrm{PBr}$, and $\mathrm{P2}$, respectively.

Note that $\mathrm{PP} 2$ equals the $\mathrm{PBr}$ input partial pressure due to complete conversion of $\mathrm{PBr} 3$ to $\mathrm{P} 2$.

A least squares fit to the measured kinetics yielded the following values for the Langmuir-Hinshelwood parameters. 
$\mathrm{K}_{r 1}=\exp [-27000 / \mathrm{T}+24.72]$
$\mathrm{K}_{r 2}=\exp [-29700 / \mathrm{T}+27.15]$
$K_{B}=\exp [24500 / \mathrm{T}-27.44]$
$K_{P}=\exp [10700 / \mathrm{T}-13.52]$
$\mathrm{K}_{P 2}=\exp [23000 / \mathrm{T}-22.20]$

$\mathrm{Ea1}_{\mathrm{a}}=224 \mathrm{~kJ} / \mathrm{mole}$
$\mathrm{Ea2}=247 \mathrm{~kJ} / \mathrm{mole}$
$\Delta \mathrm{HB}=204 \mathrm{~kJ} / \mathrm{mole}$
$\Delta \mathrm{HP}=89 \mathrm{~kJ} / \mathrm{mole}$
$\Delta \mathrm{HP2}=191 \mathrm{~kJ} / \mathrm{mole}$

Ea1, Ea2 : reaction activation enthalpy for reaction $r 1$ and $r 2$, respectively. $\triangle \mathrm{HB}, \triangle \mathrm{HP}, \triangle \mathrm{HP2}$ : heat of adsorption for $\mathrm{BBr}, \mathrm{PBr}$, and $\mathrm{Pz}$, respectively.

These energies, 1.e. (3)-(7) remain to be explained in terms of the observed Langmuir-Hinshelwood reaction mechanism. The calculated energies from the Langmuir-Hinshelwood reaction mechanism shall be assigned involving chemical bonds between specles. In Table 1 several binding energies are listed which will be shown to be important in the assumed Langmuir-Hinselwood kinetics. A tentative model is given below.

Table 1. Binding energies of boron, phosphorus, and hydrogen $/ 11 /$.

\begin{tabular}{|c|c|c|}
\hline Bond & Energy $/ \mathrm{kJ} / \mathrm{mole}$ & From: \\
\hline $\begin{array}{l}B-B \\
P-P \\
P=P \\
B-P \\
B-P \\
H-H\end{array}$ & $\begin{array}{r}190-230 \\
210-230 \\
488-496 \\
200-250 \\
10-100 \\
435-447\end{array}$ & $\begin{array}{l}\text { Boron sublimation; } B(s) \longrightarrow B(g) \\
\text { Phosphorus (black) sublimation; } P(s) \longrightarrow P(g) \\
\text { Diphosphorus dissociation; } P 2(g) \longrightarrow 2 P(g) \\
\text { BP(s) dissociation; } B P(s) \longrightarrow B(g)+P(g) \\
X 3 B-P Y 3(g) \longrightarrow B X 3(g)+P Y 3(g) ; d i s s o c i a t i o n / 12 / \\
\text { Hydrogen dissociation; } H 2(g) \longrightarrow 2 H(g)\end{array}$ \\
\hline
\end{tabular}

${ }^{1}$ Note that the binding energy in the Langmulr-Hinshelwood reaction mechanism should be taken per mole $P$ or $H$. The dissoclation energy however is given in $\mathrm{kJ} / \mathrm{mole} \mathrm{Pz}$ or $\mathrm{Hz}$.

The reaction mechanism below $925^{\circ} \mathrm{C}$. The value of $\Delta \mathrm{HB}, 1$. e. $204 \mathrm{~kJ} / \mathrm{mole}$ (Eq. (5)) corresponds to the heat of adsorption of $\mathrm{BBr}$ on $\mathrm{BP}$. This heat of adsorption seem to be in line with the binding energy of B-P or B-B (Table 1). Hence, the heat of adsorption of $\mathrm{BBr}$ can be assigned to $\mathrm{B}-\mathrm{P}$ or $\mathrm{B}-\mathrm{B}$ bond formation. Similarly the value of $\Delta \mathrm{Hp}$, i.e. $89 \mathrm{~kJ} / \mathrm{mole}$ (Eq. (6)), which seems to lie between that of a physisorption and a chemisorption process, corresponds to the heat of adsorption of PBr3 on BP. This heat of adsorption is similar to the binding energy of B-P found in adducts $X_{3} B-P Y 3$ (Table 1 ), where $X$ and $Y$ represent either halogen or hydrogen. Hence, the heat of adsorption $\triangle \mathrm{HP}$ can be assigned to $\mathrm{B}-\mathrm{P}$ bond formation with binding energy as observed in $\mathrm{X}_{3} \mathrm{~B}-\mathrm{PY} 3$. The reaction activation enthalpy $E_{a 1}, 1 . e .224 \mathrm{~kJ} / \mathrm{mole}$ (Eq. (3)), is similar to the binding energy of $P-P$ (Table 1). Hence, the reaction activation enthalpy is necessary to break a $P-P$ bond. This $P-P$ bond breaking is tentatively assigned to a desorption of a chemisorbed phosphorus species from the surface. Using the results of equations (3), (4), and (6) it is possible to calculate the phosphorus surface concentration / $/$. The calculations reveal the surface seems to be covered almost completely by phosphorus. Thus it is not surprising to find that the reaction rate is controlled by a desorption process involving phosphorus. Consequently this desorption leaves a free adsorption site on which $\mathrm{BBr}$ or $\mathrm{PBr} 3$ can adsorb. The adsorbed $\mathrm{BBr}$ species takes care of the progression of the reaction. The model is shown in the reactions (8)-(13). Gaseous species are unlabeled, * represents a free adsorption site, the label * indicates an adspecies, and <BP> represents solld cubic boron monophosphide. Reactions (9) and (12) are written as overall reaction steps since we cannot assign how $\mathrm{H} 2$ is involved in separate reaction steps. Neither is it possible to calculate an activation enthalpy of reactions (9) and (12). However, the activation enthalpies of 
reactions (9) and (12) are certainly much lower than the observed activation enthalpy of reaction (10) since this was the rate controlling step. Although the nature of the adspecies $B^{*}$ and $P^{*}$ is unknown, they are assumed to be monoatomic. The nature of the phosphorus adspecies will be discussed later.

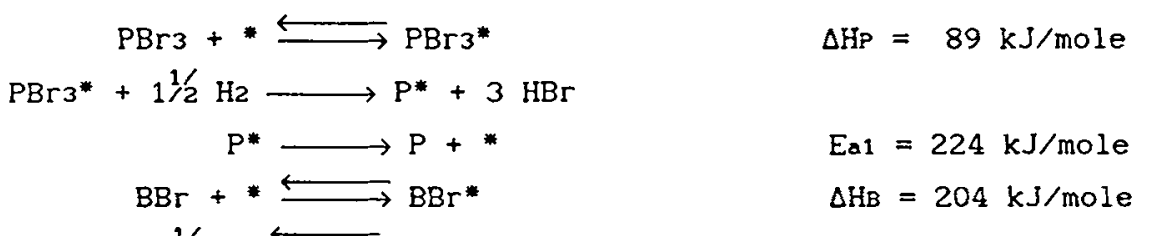

$\mathrm{BBr}^{*}+1 / 2 \mathrm{H} 2 \longleftrightarrow \mathrm{B}^{*}+\mathrm{HBr}$

$\mathrm{P}^{*}+\mathrm{B}^{*} \longrightarrow\langle\mathrm{BP}\rangle+2^{*}$

The reaction mechanism above $925^{\circ} \mathrm{C}$. The $\Delta \mathrm{HB}_{\mathrm{B}}$ value observed by the least squares fit of equation (1) is taken to be the same for equation (2). This assumption can be justifled by a complete fit of equation (2), where we found $\Delta \mathrm{HB}$ being the same within the error of the measurements. The $\Delta H_{p 2}$ value, 1.e. $191 \mathrm{~kJ} /$ mole (Eq. (7)) corresponds to the heat of adsorption of P2. This heat of adsorption equals almost twice the heat of adsorption of $\mathrm{PBr}$ found for low temperature depositions. Thus, per mole $P$ the heat of adsorption of $P 2$ equals almost the heat of adsorption of PBr3. In the assumed Langmuir-Hinshelwood reaction mechanism (Eq. (2)) dissociation should occur. The dissociation of P2 in the gas phase needs $488-496 \mathrm{~kJ} / \mathrm{mole} \mathrm{P} 2$ (Table 1). According to catalysis the dissociation energy of $\mathrm{P} 2$ is assumed to be the same at the surface. The dissociation energy of $\mathrm{P2}$, 1.e. $488-496 \mathrm{~kJ} / \mathrm{mole} \mathrm{P} 2$, is equal to $244-248$ $\mathrm{kJ} / \mathrm{mole} \mathrm{P}$ formed upon dissociation. This value is in line with the observed activation enthalpy of equation (2), 1.e. $247 \mathrm{~kJ} / \mathrm{mole}$. Hence, the dissociation of $\mathrm{P} 2$ on the surface seems to be the rate limiting step at high temperatures. The monoatomic phosphorus formed in this dissociation process is assumed to be physisorbed. We already know from the low temperature kinetic measurements that the desorption energy of chemisorbed phosphorus is $224 \mathrm{~kJ} / \mathrm{mole} P$ (Eq. (10)). Neglecting a probably small adsorption activation enthalpy, the adsorption energy equals the desorption energy by changing sign. Therefore, the chemisorbed phosphorus species $P^{*}-$ level has already been determined (Fig. $4)$. i.e. two times $224 \mathrm{~kJ} / \mathrm{mole} \mathrm{P}$ below the $2 \mathrm{P}+2^{*}-$ level. The energy difference $\triangle H P C$ between physisorbed and chemisorbed phosphorus, $\mathrm{P}^{\mathrm{x}}$ and $\mathrm{P}^{*}$, respectively, becomes therefore $(2 * 224-191) / 2=129 \mathrm{~kJ} / \mathrm{mole} \mathrm{P}$. The activation enthalpy to free an occupied surface site from phosphorus, i.e. $224 \mathrm{~kJ} / \mathrm{mole}$ will be less important relative to the observed activation enthalpy, $1 . e .247 \mathrm{~kJ} / \mathrm{mole}$. The reaction mechanism can be written by reaction steps (11)-(13) and the following reactions:

$2 \mathrm{PBr} 3+3 \mathrm{H} 2 \longrightarrow \mathrm{P2}+6 \mathrm{HBr}$

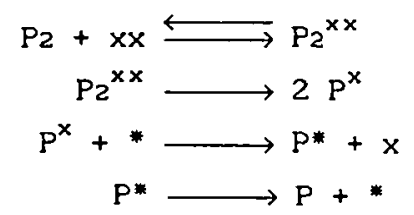

$$
\begin{aligned}
\Delta \mathrm{HPZ}_{2} & =191 \mathrm{~kJ} / \mathrm{mole} \mathrm{P} 2 \\
\mathrm{E}_{\mathrm{a} 2} & =247 \mathrm{~kJ} / \mathrm{mole} \\
\Delta \mathrm{HPC} & =129 \mathrm{~kJ} / \mathrm{mole} \mathrm{P} \\
\mathrm{E}_{\mathrm{a} 1} & =224 \mathrm{~kJ} / \mathrm{mole}
\end{aligned}
$$

The symbols are the same as described for reactions (8)-(13), $x$ represents a free physisorption site, and the label $x$ indicates a physisorbed adspecies. In Figure 4 both models are summarized in an energy versus reaction path plot. The value $\triangle H P C$ is also used for the energy difference of adsorbed $P B r 3$ to chemisorbed phosphorus $P^{*}$. 


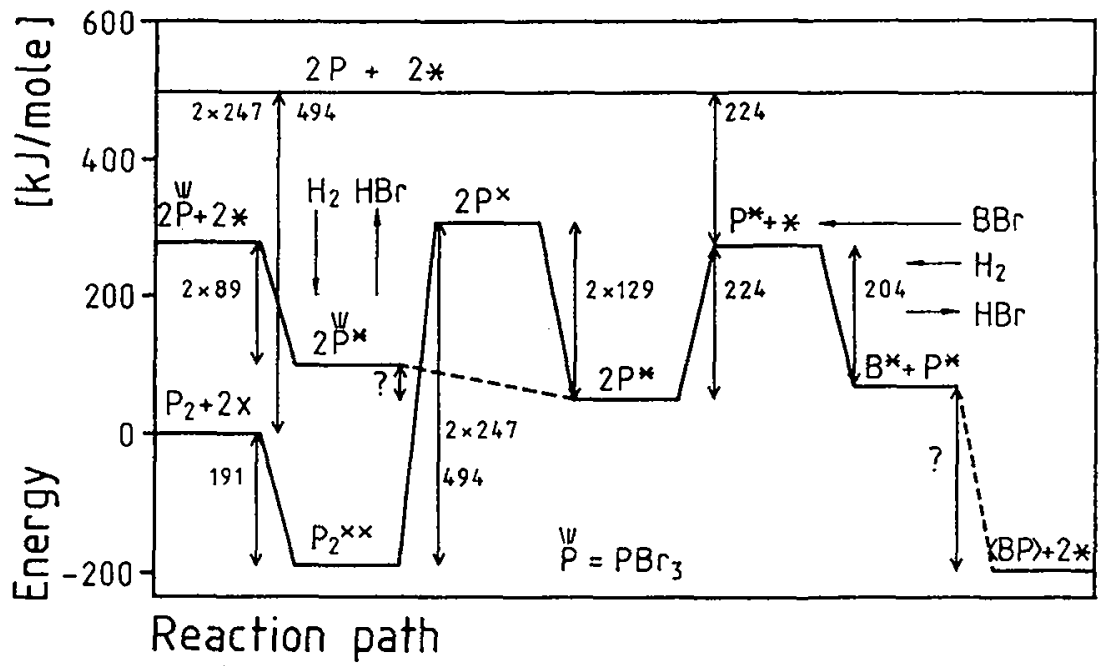

Fig. 4. Reaction path scheme with heats of adsorption for the corresponding species and activation enthalpies for both reaction mechanisms.

Symbols as mentioned in the text.

The model of dissociation after physisorption is discussed in Ref. 9 . The chemisorbed phosphorus atoms $P^{*}$ show up an endothermic adsorption relative to P2. The existence of endothermic adsorption was already observed and discussed by de Boer /13/ and Thomas /14/. The model was extensively discussed along with dissociative adsorption of $\mathrm{Hz}$ on several different substrates, with initially physisorption of $\mathrm{Hz}$. De Boer /13/ and Thomas /14/ explained the existence of endothermic adsorption by the change of entropy on adsorption. Thomas /14/ concluded that only endothermic chemisorption is possible.

Experimentally, the dissociation of $B P$ into BxP and $P 2$ can be understood by this reaction scheme (Fig. 4), due to the low lying level of physisorbed Pz. We also can understand the formation of only n-type semiconducting BP /7/ by incorporation of phosphorus, which is avallable in excess at the surface. This excess phosphorus precludes $p$-type semiconducting BP formation. However, if several free surface sites become avallable for $\mathrm{BBr}$ adsorption, 1.e. on going to higher temperatures or lower $\mathrm{PBr} 3$ input partial pressure, $\mathrm{B} \times \mathrm{P}$ will be formed (Fig. 1) due to the high activation enthalpy of $\mathrm{P} 2$ dissociation. Hence, BxP formation will be formed though there is an excess of phosphorus avallable as P2.

We have also obtained the growth rates of polycrystalline BP as a function of the hydrogen partial pressure. From Figure 5 which shows the results, it follows that at temperatures below $925{ }^{\circ} \mathrm{C}$ the reaction order in $\mathrm{Hz}$ is $1 / 2$ whereas at temperatures above $925^{\circ} \mathrm{C}$ this order shifts to zero.

The order $1 / 2$ shows up if equation (12) would be limiting the growth rate. However, this reaction cannot account for an order -1 and $-1 / 2$ for the $\mathrm{PBr} 3$ reactant. Hence, equation (12) will not be rate limiting. The observed transition in reaction order in the phosphorus reactant on going to higher temperatures concomitant with a change in reaction order in hydrogen, can be understood from the behavior of the main phosphorus specles $P^{*}$ present on the surface. In the outline of the reaction mechanism given above, this species was unspecified. The observed order in $\mathrm{H}_{2}$ suggests that $\mathrm{P}^{*}$ probably is covalently bound $\mathrm{PH}^{*}$. 


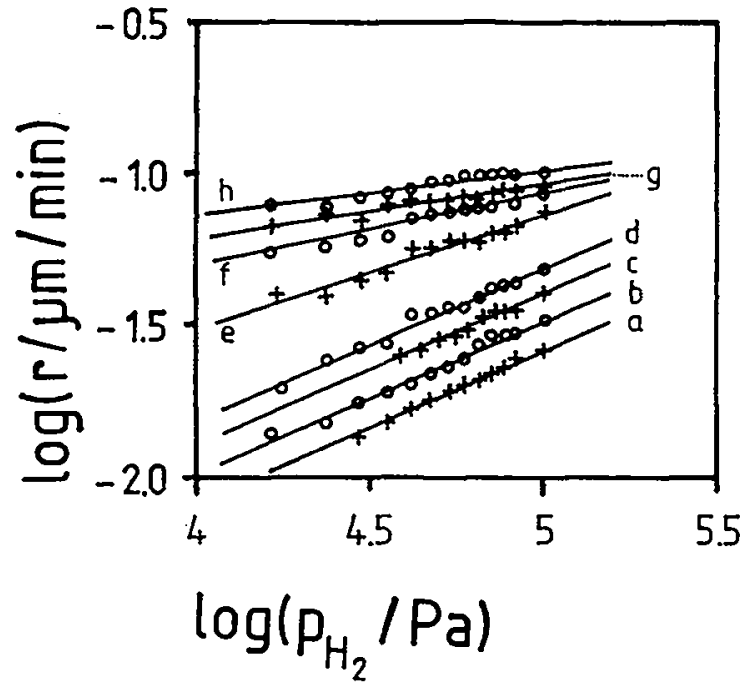

Fig. 5. Logarithmic plot of the growth rate $r$ versus H2 pressure for several temperatures $\left({ }^{\circ} \mathrm{C}\right)$ at constant $\mathrm{BBr} 3$ and $\mathrm{PBr} 3$ pressure of 45 and $405 \mathrm{~Pa}$ respectively. a: 828; b: 852; c: 878; d:902; e: $928 ;$ f: $952 ; \mathrm{g}: 977$; h: 1004.

We calculated the surface concentration by assuming a change in enthalpy and entropy of the gas specles on adsorption. The enthalpy change is taken to be the observed bond energy as calculated by the least squares fit. The entropy change is calculated by the loss of translation and rotation entropy of the gas species and the gain of vibration entropy of the adspecies. The complete model and the results will be published elsewhere.

The most striking result of the calculations is the almost complete coverage of the surface by $\mathrm{PHz}$ adspecies bound to boron atoms as well as to phosphorus atoms already incorporated in the substrate. Desorption of excess PH2*, necessary to free an occupled surface site, is controlled by a gas phase reaction of $\mathrm{PH} 2$ with $\mathrm{H} 2$ to form $\mathrm{PH} 3$ according to equation (20). Equation (20) is given as an overall reaction since it is not known how $\mathrm{H} 2$ reacts in separate steps. $\mathrm{PH}_{3}$ is calculated to be present in the gas phase in considerable quantities $/ 7 /$.

$\mathrm{PH}^{*} \leftrightarrows \mathrm{PHz}+*$

$\mathrm{PH} 2+1 / 2 \mathrm{H}_{2} \longrightarrow \mathrm{PH} 3$

The P-P bond breaking needed for desorption of excessively present $\mathrm{PH} 2$ and hence for the progression of the reaction is consistent with the reaction activation enthalpy of $224 \mathrm{~kJ} / \mathrm{mole}$. However, the reaction can also occur by initial adsorption of the $\mathrm{PH} 3$ species formed by the reaction with $\mathrm{H} 2$ (see equation (21)). Here too, the role of $\mathrm{Hz}$ is not known in separate steps.

$\mathrm{PH}^{*}+1 / 2 \mathrm{H} 2 \longleftarrow \mathrm{PH}_{2}^{*} \longrightarrow \mathrm{PH}_{3}+*$

The desorption activation enthalpy, however, will have the same order of magnitude as the heat of adsorption of PBr3, i.e. $89 \mathrm{~kJ} / \mathrm{mole}$. This means that this $P-P$ bond breaking cannot explain the reaction activation enthalpy. However, Table 1 shows that the dissociation energy of $\mathrm{H} 2$ is $435-447 \mathrm{~kJ} / \mathrm{mole}$ $\mathrm{H} 2$, or 217-224 $\mathrm{kJ} / \mathrm{mole} \mathrm{H}$. The dissociation energy, i.e. $217-224 \mathrm{~kJ} / \mathrm{mole} \mathrm{H}$ is in good agreement with the observed activation enthalpy at low temperature (Eq. (3)). Hence in the event of initial adsorption of $\mathrm{PH} 3$ formed by the reaction of adsorbed $\mathrm{PH} 2$ with gaseous $\mathrm{Hz}$ the reaction is controlled by dissociation of $\mathrm{H}$. 
The decrease of the reaction order towards higher temperatures can be understood by the nature of the reaction. In this temperature range the reaction activation enthalpy increases to $247 \mathrm{~kJ} / \mathrm{mole}$ presumably due to $\mathrm{P}=\mathrm{P}$ bond breaking. This high activation enthalpy will mask the lower activation enthalpy of $224 \mathrm{~kJ} / \mathrm{mole}$, resulting in a reaction rate which will become independent on the hydrogen partial pressure under study. Both models described above predict a zero order in hydrogen towards higher temperatures. Hence, to discriminate between these alternative mechanisms, growth rates must be measured as a function of $\mathrm{BBr} 3$, and $\mathrm{PBr} 3$ partial pressure and temperature at several different $\mathrm{H} 2$ partial pressures.

\section{4. - Conclusions.}

Polycrystalline cubic BP can be synthesized by Chemical Vapor Deposition of $\mathrm{BBr} 3, \mathrm{PBr} 3$ in a reducing atmosphere of hydrogen. The regime of $\mathrm{BP}$ formation determined by temperature and molar ratios of reactants, however, is narrow. In the temperature range between 1050 and $1350 \mathrm{~K}$ the deposition rate obeys Langmuir-Hinshelwood kinetics. At low temperatures PBr3 is the main adsorbed species competing for the same adsorption sites with $\mathrm{BBr}$. The activation enthalpy, i.e. $224 \mathrm{~kJ} / \mathrm{mole}$, is due to surface-phosphorus bond breaking of chemisorbed phosphorus species. At higher temperatures when the main adsorbed species is $\mathrm{P2}$, which adsorbs dissociatively and competes for the surface sites with $\mathrm{BBr}$, the reaction is determined by an activation enthalpy of $247 \mathrm{~kJ} / \mathrm{mole}$ due to $P=P$ bond breaking.

$A$ change of the order in PBr3 at high input from -1 to $-1 / 2$ towards higher temperatures is accompanied by a change of the order in hydrogen from $1 / 2$ to zero. The surface phosphorus species is probably $\mathrm{PH} 2$ which will desorb on reaction with $\mathrm{H} 2$ resulting in an activation enthalpy of $224 \mathrm{~kJ} / \mathrm{mole}$ due to $\mathrm{P}-\mathrm{P}$ bond breaking and an order in $\mathrm{H} 2$ of $1 / 2$. The activation enthalpy of $224 \mathrm{~kJ} / \mathrm{mole}$ can also be explained by dissociation of $\mathrm{H}_{2}$ to form $\mathrm{PH}_{3}$ which will desorb with an activation enthalpy of the order of magnitude of the heat of adsorption of PBr3, i.e. $89 \mathrm{~kJ} / \mathrm{mole}$.

At temperatures above $925{ }^{\circ} \mathrm{C}$ the reaction become independent of the $\mathrm{H} 2$ partial pressure since $\mathrm{H} 2$ is not involved in the rate limiting step, 1.e. $P=P$ bond breaking. Hence, the order in $\mathrm{H} 2$ becomes zero on going to higher temperatures.

References.

11/ Williams F.V. and Ruehrwein R. A., J. Am. Chem. Soc., 82 (1960) 1330.

/2/ Burmeister R.A. and Greene P.E., Bull. Am. Phys. Soc., 10 (1965) 1184.

/3/ Park H., Ph. D. Thesis, Duke University (1983).

14/ Kelder E.M., Goossens A., van der Put P.J., and Schoonman J., Proc. EuroCvd seven, C5-567 (1989).

15/ Wang C.C., Cardona M., and Fischer A.G., RCA Rev., 25 (1964) 159.

/6/ Mizutani T., Asano H., Nishinaga T., and Uchiyama S., Jap. J. Appl. Phys., 16 (1977) 1629.

17/ Kelder E.M., Goossens, A., van der Put P.J., and Schoonman J., Proc. Int. Conf. CVD (CVD-XI, Electrochem. Soc.), (1990) 120.

18/ Hannay N.B., Treatise on Solid State Chemistry, Plenum Press, New York, (1975), Vol. 5, Ch. 6.

19/ Ponec V., Knor 2., and Cerny S., Adsorption on Solids, (English translation, Smith D. and Adams N.G., Eds.), Butterworths, London (1974), Chapters 8 and 9.

/10/ Vandenbulcke L. and Vuillard G., J. Electrochem. Soc., 124 (1977) 1931. 11/ JANAF, Thermochemical Tables, J. Phys. and Chem. Ref. Data 14 (1985).

112/ Finch A. Gardner P.J., and Sen Gupta K. K., Inorg. Chem., 6 (1967) 386.

113/ De Boer J.H., Advan. Catalysis, 9 (1957) 472.

/14/ Thomas J.M., J. Chem. Educ., 38 (1961) 138. 